\title{
LA RAZÓN POÉTICA EN ZAMBRANO: ALGUNAS CLAVES INTERPRETATIVAS PARA DESENTRAÑAR SU SENTIDO*
}

\author{
Gladis del Socorro García Restrepo** \\ doi: 10.11144/Javeriana.uph36-73.rpmz
}

\section{RESUMEN}

El presente artículo aporta a la comprensión del sentido de la razón poética en la obra de María Zambrano desde una aproximación hermenéutica. La razón poética se constituye en el eje del pensamiento filosófico de Zambrano y, a su vez, se vislumbra como una vía que propone la autora para construir una mirada más humana de la racionalidad, menos arrogante y que enriquece las dimensiones ontológicas y antropológicas del hombre. La reflexión se presenta en tres momentos: en el primero se intentará mostrar una reforma al entendimiento, que involucra la vida humana de forma integral, de tal manera que la razón trascienda y permita comprender la complejidad histórica del hombre y la urgente necesidad de volver sobre sí mismo. En el segundo se centrará la atención sobre el nuevo humanismo zambraniano, sustentado en la razón poética y misericordiosa, como antídoto ante el fantasma de la guerra, y el tercero se detiene en la obra Claros del bosque para indicar al lector los tres momentos hermenéuticos a los que posiblemente se enfrentará, al intentar comprender el reino de la razón poética.

Palabras clave: María Zambrano; razón poética; poesía; bosque; amor

Artículo derivado de la tesis de Doctorado en Filosofía, titulada La relación entre el pensamiento filosófico y la acción educativa en la racionalidad poética de Maria Zambrano, de la Universidad Pontificia Bolivariana, Colombia.

" Universidad de Antioquia, Medellín, Colombia.

Correo electrónico: gladys.garcia@udea.edu.co

Para citar este artículo: García Restrepo, G. S. (2019). La razón poética en Zambrano: algunas claves interpretativas para desentrañar su sentido. Universitas Philosophica, 36(73), 215-233. ISSN 0120-5323, ISSN en línea 2346-2426. doi: 10.11144/Javeriana.uph36-73.rpmz 


\title{
ZAMBRANO'S POETIC REASON: A FEW INTERPRETIVE KEYS TO UNRAVEL ITS MEANING
}

\begin{abstract}
This paper attempts a renewed understanding of the concept of poetic reason, key in María Zambrano's philosophical writings, from a hermeneutical approach. Poetic reason might be seen in this light as a gateway to a different kind of rationality, one that might help to enrich its ontological and anthropological implications, and overcome the hubris that has been historically ingrained in this concept. The paper is structured in three parts: in the first one, an attempt will be made to show a reform of the understanding, which involves human life integrally, in such a way that reason transcends and makes it possible to understand the historical complexity of man and the urgent need to return to oneself. In the second, special attention will be focused on Zambrano's new humanism, based on poetic and merciful reason, as an antidote to the ghost of war. And the third section delves in the work Claros del bosque to point to the reader the three hermeneutical moments that they will possibly face when trying to understand the realm of poetic reason.
\end{abstract}

Keywords: María Zambrano; poetic reason; poetry; forest; love 


\section{Introducción}

YA en los albores de su pensar, María Zambrano dejaba entrever su incomodidad frente al racionalismo deshumanizado con el que le correspondió conversar y en repetidas ocasiones discutir. Discusión que inició muy temprano en su vida, haciéndose más evidente y fervorosa en los años de su formación filosófica, y que se prolongó en el día a día, hasta su muerte. Su incomodidad emerge ya desde 1928, en "La ciudad ausente", en donde expresa: "todas las cosas son allí preludios no más, puntos de partida, problemas para la mirada que se hace ascética" (Zambrano, 2004, p. 58). Precisamente ese ensayo se consolida como preludio de su razón poética, cuya semilla cargada de sentido va esparciendo por toda su obra en actitud delicada, estratégica y asistemática. Su legado invita permanentemente a ir más allá de las circunstancias en las que se ve envuelto el ser humano, sin otro afán que el de desentrañar de su ser el logos, transformado en espíritu por gracia de la poesía, vista esta como experiencia mística que, en palabras de Zambrano, equivaldría a la revelación del ser. Conviene en este punto retomar el pensamiento de Ortega Muñoz (1996), quien al respecto escribe:

María Zambrano propone un nuevo estilo del filosofar que denomina, como ya hemos visto, "razón poética", donde "razón" hace referencia a la tarea discursiva de la mente y "poética" alude al doble sentido de esta palabra, en primer lugar de vate, revelación del ser, de lo divino, pero además, como indica el origen de la palabra "poieo", creador con la palabra, porque solo con la palabra puede expresar lo que en su "sentir originario" se le manifiesta, se le revela (p. 233).

En esta misma línea, en el año 1930, Zambrano publica su primer libro, Horizonte del liberalismo, en el que se observan significativos y diáfanos conatos de lo que más tarde se conocería como razón poética y que tempranamente expresaba así: cuando la razón estéril se retira, reseca de luchar sin resultado, y la sensibilidad quebrada solo recoge el fragmento, el detalle, nos queda solo una vía de esperanza: el sentimiento, el amor, que, repitiendo el milagro, vuelva a crear el mundo (1996, p. 269).

Sin duda, el amor que proclama Zambrano es un amor de orden ontológico y universal, constituyéndose en cuanto tal en la fuerza que sustenta la razón poética, 
dada su capacidad trascendental, reparadora y creadora, con la que puede recrear el mundo y por supuesto al hombre, como ser en necesidad de renovar y renovarse. En este mismo texto, Zambrano (1996) se refiere al trinomio de política, razón y vida: "será revolucionaria aquella política que no sea dogmática de la razón, ni tampoco de la supra-razón; y creerá más en la vida, más en la virtud de los tiempos que en la aplicación apriorística de unas cuantas fórmulas" (p. 212). En esta declaración, y a modo de vaticinio, Zambrano vislumbraba los enormes estragos que puede llegar a producir el despliegue de una política en la que se imponga una razón que, por su condición, no le deje espacio a aquella otra razón empeñada en dar cuenta del hombre como ser integral; vaticinios vueltos realidad, padecidos no solo por ella, sino también por su familia y sus conciudadanos.

Que Zambrano ya daba pistas en su primer libro de lo que sería un proyecto filosófico volcado a la razón poética es más que una mera elucubración. Al respecto, señala Bundgård (2005):

esa fue la meta de Zambrano desde 1930 hasta su muerte, a pesar de la línea divisoria del antes y después que para ella supuso el trágico exilio. Ese sería el proyecto filosófico de Zambrano cuyo eje se encuentra en la metafísica experimental de la razón poética ya actuante en Horizonte del liberalismo (p. 38).

En 1934, la filósofa publica Hacia un saber sobre el alma, donde aparecen, según declara en una nota a la edición del año 2000, "en su germinación, esas dos formas de razón -la mediadora y la poética- que han guiado todo mi filosofar" (Zambrano, 2000a, p. 9). Esta declaración conlleva, en tono de anunciación, la meditada evolución de su pensamiento en el que da cuenta nuevamente de una retadora razón, caracterizada por ser mediadora y frente a la cual manifestaba en los últimos años de su vida: "toda razón ha de ser mediadora entre la nada y el ser, entre la soberbia de la vida y su acabamiento, su humillación" (Zambrano, 1989b, p. 129). De acuerdo con Revilla (2003), "Zambrano sugirió, sobre todo, la necesidad de un saber acerca del alma, trozo del cosmos en nosotros desatendido y olvidado, pero, por su naturaleza misma, lugar privilegiado de mediación, depositario de razones y cuya voz es la poesía” (p. 97). Una razón que, al no ser arrogante, y declararse mediadora y lejana de protagonismos, procura suavizar en importante medida el ímpetu de la razón dominante en la que ha sido atrapado 
el hombre, en su empeño por conjugar en primera y única persona verbos como existir, progresar, descubrir, soñar, entre otros. Frente al desconocimiento de la urgencia de construir un nosotros que conduzca a un pensamiento colectivo, ajeno a los intereses propios de la errónea interpretación de la autonomía en la que se privilegian los individualismos, señala Zambrano (1992): "convivir quiere decir sentir y saber que nuestra vida, aun en su trayectoria personal, está abierta a la de los demás, no importa sean nuestros próximos o no" (p. 16). Se intuye en esta declaración una invitación a la acción, a la manera como en la cotidianidad podría hacerse efectiva la razón poética; provoca el tránsito de la palabra escrita a la experiencia humana, del mero pensar al hacer, que ya no sería en modo improvisado, sino que estaría mediado por la conciencia, variante que le infunde al ser humano una nueva manera de aproximarse a la realidad. $\mathrm{Al}$ respecto, escribe Gómez (1992): "Zambrano también tiene una nueva idea del ser. El objeto de su filosofía es el ser como realidad, realidad que es la vida, que es la realidad toda en su sentido más amplio y que parte de la realidad de lo sagrado" (p. 56). La de María Zambrano, sostienen Larrosa y Aparici (2000), es una razón vital que se hace, por su propia necesidad interna, razón poética, pero que, en cuanto tal, precisa interrogar constantemente los diferentes modos de su encarnación en la vida.

\section{Razón poética: una nueva forma del entendimiento}

EL RECORRIDO REALIZADO POR ZAMBRANO, que se ha señalado hasta aquí, la llevó a un destacado puerto en su obra, al escribir en 1937 el ensayo "La reforma del entendimiento" (1989c), en el que declara:

En los momentos críticos de la historia se ha hablado siempre de una "Reforma del entendimiento", de una crítica que el intelecto se hace a sí mismo, volviéndose sobre sí, para tomar conciencia de sus propias fuerzas y más aún, de sus deficiencias. Revela esta actitud humana dos actitudes al parecer contrarias: desconfianza y fe en la razón (p. 73).

Es esta reflexión la que anima a Zambrano en este ensayo a viajar de forma rápida pero precisa por la historia de la razón, que no ha sido otra que la historia del hombre en el contexto de su pensar. En consecuencia, la autora enuncia dos vías en virtud de las cuales se podría realizar una crítica del entendimiento: la primera, abordando la razón como instrumento y observando su estructura y 
función. En tal sentido, expresa (1989c): "volverse hacia el instrumento mismo, analizar su estructura y su funcionamiento 'puro”' (pp. 73-74). La segunda manera sería vincular al ámbito del entendimiento todo aquello que ha sido invisibilizado o velado por la razón y por tanto relegado al terreno de lo irracional, que a su vez estaría en conexión con el no-ser. Quiere decir esto que aspectos que atañen esencialmente al ser humano, particularmente lo que tiene que ver con el sentir, y que se conectan con el terreno de lo espiritual o místico, son desconocidos y hasta vituperados por la razón, que solo se ocupa de lo que puede demostrarse y verificarse en el ámbito de la ciencia: "es la cuestión de la razón y de lo irracional -comentaba Zambrano (1989c) - que se cruza con la del ser y el no ser" (p. 74).

De ahí que Zambrano entra en interlocución crítica con la historia de la filosofía, deteniendo su mirada primeramente en la cultura griega, y transitando luego por otras perspectivas filosóficas. Este recorrido le permite a la autora observar que la razón de una u otra manera ha permeado la historia del pensamiento filosófico. Encuentra también que en momentos difíciles para la humanidad, esa razón suficiente entra en tensión y por tanto amerita ser reformada. La razón poética, eje del filosofar zambraniano, emerge como respuesta a esa necesidad de reforma. $\mathrm{Al}$ respecto asegura: "Quiere decir que la razón humana tiene que asimilarse el movimiento, el fluir mismo de la historia [...] adquirir una estructura dinámica en sustitución de la estructura estática que ha mantenido hasta ahora" (Zambrano, 1989c, p. 79). Esta reforma de la razón es una invitación de Zambrano para que la actitud del ser humano en este terreno transite de la desconfianza a la fe.

En el ensayo al que se está haciendo referencia y a propósito del aporte que hace su maestro a la crítica al entendimiento, Zambrano señala: "Ortega y Gasset, en su ensayo del año 1924, 'Ni vitalismo ni racionalismo', analizando la teoría de la razón expuesta de modo clásico por Leibniz, dice: 'la razón es una breve zona de claridad analítica que se abre entre dos estratos insondables de irracionalidad"' (1989c, p. 78). Pensamientos como este han sido motivo para que se plantee la pregunta por la relación entre el raciovitalismo orteguiano y la razón poética de Zambrano, asunto frente al cual la filósofa dejó oír su voz para advertir: 
La senda que yo he seguido, que no sin verdad puede ser llamada órficopitagórica, no debe de ser, en modo alguno, atribuida a Ortega. Sin embargo, él, con su concepción del logos (expresa en el 'logos del Manzanares'), me abrió la posibilidad de aventurarme por una tal senda en la que me encontré con la razón poética; razón, quizá, la única que pudiera hacer, de nuevo, encontrar aliento a la filosofía para salvarse -al modo de una circunstancia- de las tergiversaciones y trampas en que ha sido apresada (Zambrano, 1986, p. 123).

Aquí Zambrano reconoce nuevamente la fuente fecunda de su pensar, atribuida en buena medida a Ortega y Gasset, pero a la vez deja claro el sendero por el cual viajó su pensamiento, que, gozando de características singulares, logró consolidarse como una novedosa propuesta, cuyo planteamiento está lejano de ser el correlato del filosofar de su maestro. La impronta que distinguió la razón poética se fundó y fortaleció, usando las palabras de la filósofa, en razones de amor:

se imponía, pues, al pensamiento el ofrecer, como razón, razones de amor. Un logos que constituye un punto de partida indeleble para mi pensamiento, pues que me ha permitido y dado aliento para pensar, ya por sí misma, mi sentir originario acerca de un logos que se hiciera cargo de las entrañas (Zambrano, 1986, p. 123).

La categoría de amor aparece de igual forma en "La guerra, de Antonio Machado", ensayo escrito en el mismo año que "La reforma del entendimiento", en el que la escritora hace una clara apuesta por la razón poética, expresada nuevamente en términos de "razones de amor": "razones de amor porque cumplen una función amorosa, de reintegrar a unidad los trozos de un mundo vacío; amor que va creando el orden, la ley, amor que crea la objetividad en su más alta forma" (Zambrano, 1989g, p. 68). En este contexto, no sería la sintaxis epistémica la única que daría cuenta del conocimiento humano en virtud de la razón instrumental, puesto que en la propuesta zambraniana también tiene cabida otro tipo de razón, cual es la razón poética, que propone una nueva manera de "reintegrar la unidad" y hallar por esta vía una nueva manera de aproximarnos al ámbito de la objetividad.

Con el propósito de intentar esclarecer las líneas gruesas que distinguen la propuesta de Ortega y Gasset de la de su discípula, Maillard (1992) expresa: 
más allá de la razón vital que, para Ortega, comprendía el ser de las cosas como lo que estas representan en nuestra vida, la razón-poética supone ese trato especial que se tiene con las cosas cuando se las sabe conformadoras de situaciones vitales en su aspecto más oculto (p. 31).

Pensamiento que supone que la mirada de Zambrano va más allá de la de su maestro, pues el centro de su filosofar fue la razón vital. La filósofa centra su atención en esa parte invisible del ser y de las cosas que, por su naturaleza, no puede ser llevada a una fórmula matemática o a una demostración experimental, aunque su presencia, permanentemente reflejada en el acontecer humano, sea innegable. Es esta circunstancia la que la inquieta particularmente y la lleva a formular su propuesta, que apunta a un logos que dé cuenta de lo que sucede en las “entrañas" del ser humano, muy afín al logos oculto que reconoce en el pensamiento orteguiano:

La atención a los signos no humanos está encerrada en el hombre histórico dentro de la atención que concede a las circunstancias, sin que se pare mientes en que las circunstancias pueden ofrecer una cierta revelación acerca de los elementos que las configuran y que nos piden "ser salvadas" según Ortega y Gasset, que las "descubrió" como depositarias de razón a rescatar del logos oculto (Zambrano, 2011b, p. 221).

Precisamente, el lenguaje al que acude Zambrano para referirse a algo que no puede demostrarse por la vía de la razón instrumental está poblado de poesía, intuición, revelación, metáfora, arte, creación; de todo aquello que conjuga el "no-ser”. Al respecto, argumenta Trueba (2009): “el concepto de 'no-ser' en Zambrano es de una riqueza inmensa, y quizás por ello aparece desde el principio vinculado al ámbito de la poesía, de la creación, en el que encuentra su lugar propio" (p. 389). Significa esto que no es por el sendero del conocimiento conceptual por el que la razón poética se expresa. Su lenguaje no se postra ante el concepto y por lo tanto está lejos de ocupar en su pensar un lugar único y superlativo, sumando así otra diferencia con la razón vital de Ortega, en la que el concepto ocupa un sitial sustantivo. Al respecto, sostiene Zambrano (2011a): "engendradora de musicalidad y de abismos de silencio, la palabra que no es concepto porque es ella la que hace concebir, la fuente del concebir que está más allá propiamente de lo que se llama pensar" (p. 213). 
$\mathrm{Al}$ acudir a este otro lenguaje del que hace uso Zambrano, intuimos que no es caprichoso; no fue buscado y encontrado para marcar diferencias con su maestro. Por el contrario, atiende a la necesidad de expresar lo indecible, aquello que está más allá del concepto; es otra forma de expresar lo oculto que habita el ser. En el filosofar de Zambrano, el concepto en su limitación queda invalidado para hacerse cargo de tan alta responsabilidad, a saber, la expresión de lo entrañable. En este escenario aparece la metáfora como forma del lenguaje que auxilia el intento de llevar a la luz lo que se halla en la oscuridad. En efecto, sobre esta figura literaria, Zambrano (1989b) expresa: "la metáfora es una forma de relación que va más allá y es más íntima, más sensorial también, que la establecida por los conceptos y sus respectivas relaciones" (p. 120). A medida que la razón va entrando en conexión con la experiencia humana, va haciendo tránsito hacia otro lenguaje que no es otro que el metafórico; de ahí que en esta línea sostenga Rivara (2002): para María Zambrano, hacer poética la razón requiere de una operación previa y fundamental: insertarla en un nuevo lenguaje capaz de darle ese dinamismo y esa vitalidad, esa liga con la vida, la tierra, el cuerpo y la existencia concreta del hombre; tal lenguaje es el lenguaje de la metáfora (p. 95).

Igualmente, en el estudio introductorio de Jesús Moreno Sanz (1996) al libro Horizonte del liberalismo, el autor referencia las claves prematuras del pensar zambraniano, que, por un lado, le van dando estructura a su pensar y, por el otro, se consolidan como pilares y horizonte de su búsqueda, y que nombra "razón poética”, un

desarrollo explícito que solo es precisable desde, como pronto, los primeros años 50, aunque aparezca mencionada desde el artículo de 1937 sobre La guerra de Antonio Machado, y sea ya claramente enunciada como su meta en la carta a R. Dieste de 7 de noviembre de 1944, en la que le dice: "Hace ya años, en la guerra, sentí que no eran 'nuevos principios' ni 'una Reforma de la Razón' como Ortega habia postulado en sus últimos cursos, lo que ha de salvarnos, sino algo que sea razón, pero más ancho, algo que se deslice también por los interiores, como una gota de aceite que apacigua y suaviza, una gota de felicidad. Razón poética... es lo que vengo buscando. Y ella no es como la otra, tiene, ha de tener muchas formas, será la misma en géneros diferentes" (pp. 18-19; cursivas en el original). 
Volviendo entonces al ensayo "La reforma del entendimiento", y para concluir este aparte, es preciso subrayar que Zambrano termina su disertación manifestando la necesidad de

acercar, en suma, el entendimiento a la vida, pero a la vida humana en su total integridad, para lo cual es menester una nueva y decisiva reforma del entendimiento humano o de la razón, que ponga a la razón a la altura histórica de los tiempos y al hombre en situación de entenderse a sí mismo (1989c, pp. 79-80).

\section{Razón poética: una alternativa ante el fantasma de la guerra}

En 1937, Zambrano publica "Los intelectuales en el drama de España", texto en el que se observa, entre otros, el propósito de ir al encuentro de las razones que subyacen a las ignominias de la guerra y, a su vez, preguntarse por el papel del hombre, poseedor de inteligencia, ante tan devastadora realidad. En tal sentido, señala: "la inteligencia ha perdido la conciencia de sus pecados, diríamos; ha reducido el orbe a su medida y todo le es permitido" (1989d, p. 31). En la guerra, en efecto, el ser humano pone al servicio de la destrucción su enorme potencial creativo. En ella, la naturaleza toda es agredida y las palabras respeto, conmiseración, solidaridad, piedad, caridad, vida, amor, pierden su sentido.

La guerra, vista como amenazante y penosa realidad, alimenta una vez más en la pensadora la apremiante necesidad de que el hombre vuelva su ser y su inteligencia hacia otros horizontes, con la esperanza de que un día eleve su conciencia a un nivel superior, de tal manera que pueda cuestionarse y cuestionar al mundo por sus acciones bélicas, por su deseo permanente de invasión que no solo se circunscribe a lo territorial, sino que lamentablemente logra alcanzar el interior del hombre, dejando su realidad externa e interna cargada de miserias. El fantasma de la guerra, que ha sido siempre una parte de la historia humana, le otorga a la esperanza zambraniana destacada actualidad:

Hay que esperar a que esos presentimientos del hombre nuevo sean algo más que un presentimiento, a que vaya apareciendo su realidad, a que el hombre vaya siendo otro, a que las facetas inéditas de la hombría, las zonas no usadas de la humanidad, vayan apareciendo por obra de imprevistos acontecimientos, para 
que sobre esa nueva realidad no hecha presente hasta hoy se forje, se produzca, la intuición del nuevo proyecto de ser hombre (Zambrano, 1989d, p. 38).

Se atisba en este pensar zambraniano el trayecto hacia un nuevo humanismo, permeado por la razón poética, en el que se torna posible la proyección hacia una concepción de hombre por la vía de la intuición, gracias a la cual el ser humano tiene la capacidad de presentir y presentirse. Para Zambrano, el presentimiento alberga un sentido de esperanza; su anhelo es que la irrealidad de una nueva humanidad se torne en realidad, en virtud de la integralidad de un ser que no solo es poseedor de inteligencia, sino también de espíritu, un mundo velado que lo conforma. En este sentido, Ortega Muñoz (1996) señala: "ella estaba convencida de que el hombre precisa de una revelación, y que sin ella no le es posible ni siquiera una reflexión coherente" (p. 215).

La revelación del espíritu en la poesía es uno de los pilares en los que la filósofa sustenta su propuesta. La poesía permite aproximarse a la realidad para comprenderla sin juzgarla; es una esquina desde la que es posible soñar y proponer, sin presunción, verdades que construyen porque están despojadas de todo ánimo de protagonismo y arrogancia. Verdades que, por su acento suave, parecieran a primera vista insuficientes, pero que, al ahondar en ellas, se descubren completas con sorpresa, y alcanzan así, sin pretenderlo, una mayor fuerza, fecundidad y potencial creador. Se intuye que la esencia integradora de la poesía se soporta en que proviene de una razón que no busca sustraerse para salvarse, sino que, por el contrario, camina codo a codo con aquella otra racionalidad, apabullante y demoledora, demostrando así su carácter inmensamente misericordioso:

Pero es que una de las características de tal género de razón -sostiene Zambranosería el no tomar represalias contra lo que la domina, el no tomar represalias más que en el terreno de la creación, rebasando, superando -jamás rebatiendo ni disputando-. Razón esencialmente antipolémica, humilde, dispersa, misericordiosa (1989e, pp. 125-126).

La razón zambraniana, como se ha venido mostrando, se concibe como creadora de esperanzadoras posibilidades: "la razón humana, que si no es creadora o poética, podrá ser muchas cosas lamentables, mas no razón de la vida, razón poética: creadora de nuevas aperturas" (Andreu, 2010, p. 14). En Filosofía y poesía (2010/1939), la razón poética se reafirma como columna vertebral del filosofar 
zambraniano. Aquí, la filósofa se empeña en reconciliar el pensamiento y la poesía en una sola unidad de sentido y vida, como dos realidades complementarias que constituyen al hombre: "no se encuentra el hombre entero en la filosofía; no se encuentra la totalidad de lo humano en la poesía” (Zambrano, 2010, p. 13). Surge entonces la necesidad de una propuesta en la que ambas vertientes del ser convivan armónicamente, se conjuguen de tal modo que su indiferenciación inhiba cualquier conato de protagonismo de una de las partes. Quizá continuando por el trayecto de esta búsqueda, Zambrano publica en 1944 El pensamiento vivo de Séneca (1987), obra en la que, además de actualizar el pensamiento de este sabio, muestra también la manera como se aproximó al tópico de la razón:

a lo que regresa Séneca es a la antigua fe de Heráclito de la razón como medida entre contrarios, la armonía de los contrarios. Y al ser la razón medida y armonía, la ley queda casi imposible de fijarse. De ahí, que la verdadera medida no pueda encontrarse en un dogma, sino en un hombre concreto que percibe con su armonía interior la armonía del mundo (p. 45).

Siguiendo a Zambrano en su interpretación de la razón en Séneca - entendida como medida y armonía-, se intuye que este pensador recoge en buena medida la intencionalidad de la utopía zambraniana, puesto que si se avanza por su sendero, la razón misericordiosa emergerá espontáneamente del interior del ser y serán entonces las notas melodiosas las que direccionarán el acontecer humano. Acontecer en cuyo fondo ya no habrá sitio para medir y observar los actos humanos a través de la razón impía: esta se habrá transformado en razón de amor, es decir, en razón armoniosa nacida de las entrañas, constituyéndose por tanto en el principal antídoto para toda clase de guerra, tanto aquellas que colonizan la esfera interna como externa del ser humano.

\section{El reino de la razón poética}

El CAMINO HASTA AQUí RECORRIDO nos conduce a un recodo de notable importancia en el tejido filosófico de Zambrano, la publicación de Claros del bosque (2011b/1977), cuyo título remite al paisaje ofrecido por la autora en Delirio y destino (1989a), cuando expresa: 
Y al hombre no se le ofrece nada como real, si no es en un orden, en una conexión; esto le había hecho llorar de alegría cuando lo encontró, así de pronto, en las primeras páginas leídas justo en el dintel de su adolescencia de ese libro que "robó" de la biblioteca de su padre: "Las meditaciones del Quijote" (p. 122).

Claros del bosque remite precisamente al anterior paisaje, porque al adentrarse en su lectura es imposible no recordar a Ortega y Gasset (1993), cuando en el texto "El bosque", incluido en la "Meditación preliminar" del libro que "hizo llorar de alegría" a la autora, advertía: "conforme camináis, volved rápidamente la mirada a un claro entre la espesura y hallaréis un temblor en el aire como si se aprestara a llenar el hueco que ha dejado al huir un ligero cuerpo desnudo" (p. 331). En similar narrativa metafórica, Zambrano inicia la escritura de Claros del bosque haciendo alusión al título del libro, cuyo significado -intuimos- hace referencia a la complejidad y misterio que habitan el interior del ser humano. No obstante, y a pesar de lo desconocido que se insinúa en dicho paisaje, anhela llegar en este viaje a un lugar, que en su lenguaje sería un espacio de claridad, sitio al que también anhela que otros lleguen, porque allí, según su convicción, hallarán la verdad como relevación, es decir, como expresión suprema de ese halo divino que envuelve desde lo profundo al hombre en su integridad. En tal sentido, escribe Zambrano (2011b):

es un centro en el que no siempre es posible entrar; desde la linde se le mira y el aparecer de algunas huellas de animales no ayuda a dar ese paso. Es otro reino que un alma habita y guarda. Algún pájaro avisa y llama a ir hasta donde vaya marcando su voz. Y se la obedece; luego no encuentra nada, nada que no sea un lugar intacto que parece haberse abierto en ese solo instante y que nunca más se dará así (p. 121).

Al no ser de fácil acceso el camino insinuante, pero a la vez desafiante, propuesto por Zambrano en Claros del bosque, es menester ubicarse en la posición del lector y aventurarse a vaticinar su actitud al enfrentársele, la cual podría traducirse en tres momentos hermenéuticos: inicialmente, esta sería de desasosiego y quizá de desistimiento ante el intento fallido por comprenderlo, pues este texto viene cargado de sentido y la tarea de desentrañarlo requiere, entre otras cosas, de una conexión profunda con el lenguaje, el contexto y los anhelos zambranianos. No obstante, este momento de desasosiego puede llegar a ser de notable 
trascendencia para el lector, en tanto que puede señalarle la puerta de entrada a la obra de Zambrano, que no es otra que la razón poética.

En un segundo momento, en el evento de que el lector asuma el reto de viajar por el sendero indicado, comprenderá en el trayecto que, para no abdicar de tan demandante aventura, debe acudir a una serie de elementos o pistas que se encuentran en otros escritos zambranianos. Podría decirse que, sin pretenderlo, la filósofa propone un autoexamen a su lector, pues las claves de comprensión que debe tener a la mano para caminar por el "bosque" y poder así llegar hasta el "claro" señalado, ella se las ha ido entregando asistemáticamente a lo largo de su obra. Esta segunda circunstancia también trae consigo un elemento de considerable valor para el lector, en virtud de que, al aceptar adentrarse en la lectura, acepta también volver una y otra vez sobre otros textos escritos por la autora, ya sea para hallar o ampliar el sentido, o también para confrontarlo con otras ideas expuestas por ella u otros autores, o sencillamente para escuchar la armonía que emana de Claros del bosque, como resonancia conjunta de toda su obra.

La tercera posibilidad hermenéutica se circunscribe al escenario de un encuentro propicio, que se abre para aquellos a quienes está dirigido explícitamente este texto, es decir, para aquellos buscadores asiduos de la verdad como revelación, esa verdad a la que Zambrano (2011b) apunta como el claro del bosque: "es la lección inmediata de los claros del bosque: no hay que ir a buscarlos, ni tampoco a buscar nada de ellos. Nada determinado, prefigurado, consabido" (p. 121). Pasaje que conecta de inmediato con otros escritos, como el de "San Juan de la Cruz. De la 'noche oscura' a la más clara mística” (1989f), en el que refiere: "San Juan nos muestra que se puede haber dejado de vivir sin haber caído en la muerte; que hay un reino más allá de esta vida inmediata, otra vida en este mundo en que se gusta la realidad más recóndita de las cosas” (p. 192).

La conexión que intuimos pone en relación "el claro del bosque" con el "reino más allá de esta vida inmediata”, experiencia que, según dice Zambrano, no está sujeta a la cesación de la vida fisiológica y de la que, por tanto, se puede gozar permaneciendo en las coordenadas de la materialidad humana, dada en términos de espacio y tiempo. En tal sentido, el "claro" hallado es quizá el reino de la razón poética; lugar que metafóricamente sería aquel en el que el hombre, al sentirse transformado y en ocasiones trascendido, asume la tarea de cambiar su mirada frente al mundo por una más comprensiva, justa y misericordiosa, por 
lo tanto, más amorosa. De esta manera, la paz y la armonía allí alcanzadas y que con seguridad habrán tocado las fibras más recónditas de su ser, podrán ser lo suficientemente fecundas como para alcanzar todos los espacios habitados por él y los demás seres que conforman la naturaleza.

De otro lado y volviendo sobre el mismo ensayo, "San Juan de la Cruz. De la 'noche oscura' a la más clara mística" (1989f), se encuentra otro aparte sobre el que es preciso llamar la atención, por los elementos que ofrece para comprender más ampliamente el significado de la razón poética:

Y esta perfecta objetividad del amor está clarísimamente expresada en san Juan y no por azar: " $\mathrm{iOh}$ cristalina fuente - si en esos tus semblantes plateados - formases de repente - los ojos deseados - que tengo en mis entrañas dibujados!" [...] Perfecta objetividad del amor, que lo es también de la poesía, pues el nexo de la mística con la poesía radica aquí precisamente; en que al ser una mística clara lleva aparejada la presencia de su objeto, que se muestra poéticamente. La definición de la poesía podría ser esta, pues no hay poesía mientras algo no queda en las entrañas dibujado (p. 193).

Si nos movemos en la definición dada por Zambrano de la poesía, podría intuirse entonces que solo quien llega al "claro del bosque", entendido este como la representación simbólica del interior del hombre, podrá poetizar su vida, o mejor dicho, la experiencia misma de caminar hacia el "claro" es ya una acción que solo puede ejecutarse si está mediada por la poesía. Por lo tanto, en el pensamiento zambraniano el terreno en el que mejor se mueve la poesía es el místico, de ahí que sea comprensible por qué en Notas de un método, publicado en 1989, dos años antes de su muerte, la autora (1989b) manifestara:

De la razón poética es muy difícil, casi imposible, hablar. Es como si hiciera morir y nacer a un tiempo; ser y no ser, silencio y palabra, [...] el sentir la vida, donde está y donde no está, o donde no está todavía. En este "logos sumergido", en eso que clama por ser dentro de la razón (p. 130).

\section{Consideración final}

ESTE ARTÍ́CULO HA ESTADO DEDICADO a desentrañar el sentido de la razón poética en la obra de María Zambrano, asumiendo, como ella bien lo expresa, 
que "de la razón poética es muy difícil, casi imposible hablar" y que, por tanto, como lo señaló Tello (2015), su poética parece imprecisa, y depende de la atención que cada uno ponga en ella. Aún con estas consideraciones, se intuye que en la esencia del "claro" propuesto por Zambrano yace, a la espera de salir a la luz, ese "no-ser" expresado en la razón poética, cuya materialización conlleva el sueño de un nuevo humanismo. Su puesta en marcha reclama a gritos un hombre renovado, dispuesto a transformarse y transformar el mundo por la gracia del amor; argumento soportado en el aliento esperanzador que emana el pensar zambraniano: "abrir camino es la acción humana entre todas; lo propio del hombre, algo así como poner en ejercicio su ser y al par manifestarlo, pues el propio hombre es camino, él mismo" (Zambrano, 1992, p. 31). Este "claro en el bosque" propuesto por Zambrano puede ser entendido como una recompensa para quien asume, en clave de esperanza, el reto de aventurarse por un sendero desconocido, pero presentido y anhelado, siendo su única luz la del amor vuelto verdad en espera de ser revelada. Podría decirse, a modo de metáfora, que de dicho amor surge una experiencia, que una vez vivida individual y colectivamente, actuaría como bálsamo para sanar las heridas que históricamente han habitado el corazón del hombre:

Es la interioridad atormentada y que no reposa, pues de ella mana ese hombre interior que quiere realizarse aquí abajo, ese clamor desde lo profundo por ser; que una vez que halla la verdad quiere existir en ella y dentro de ella, existir siempre (Zambrano, 2000b, p. 77).

Hallar la verdad por la vía de la revelación es la promesa de Zambrano para aquellos que, dando curso a su propia razón poética, asuman en su vida la tarea de guardabosques, que conlleva no solo el cuidado del "bosque", sino también del "claro", su hallazgo inesperado, donado por "razones de amor". Promesa que se extiende a todos los seres humanos, con la esperanza de que su vivencia, comprometida y profunda, abra la puerta a un nuevo nacimiento y a una inocencia lúcida, consciente de su propio milagro. De ahí que Zambrano (2011b) sostenga: "solo el hombre dotado de un corazón inocente podría habitar el universo” (p. 187).

Para cerrar esta reflexión, vale la pena recordar el énfasis que hace Zambrano (1989b) en la gran dificultad, casi imposibilidad, de aprehender la razón poética 
a través del discurso. De ahí que Moreno Sanz (1995) pueda decir con elocuencia que

las palabras, más allá de su "cosificación", más allá de su violento avasallar la realidad, parecen querer ser unos percutir y repercutir admirativos, donde la propia "veneración" se erige en clave del pensar. Esta es la grave (o elástica) dificultad que planea no solo sobre la propia escritura de esta autora, sino que parece estar interfiriendo en casi todos los escritos que sobre ella se han hecho, abocándolos (quizá también a este mío) a ser "malas" (por erradamente explícitas u opacamente glosatorias) transcripciones que ni dicen, ni ocultan, ni indican y ni siquiera rozan ni remotamente la mirada que tratan de hacer ver, ni la sintonía que quisieran hacen oír. Acaso -se nos sigue avisando- de lo que no se puede hablar es mejor callar. Callar y cantar, si es que aún fuese posible (p. 175).

Siguiendo este pensamiento de Moreno, es preciso señalar que aventurarse a proponer algunas claves interpretativas para desentrañar el sentido de la razón poética en María Zambrano es un viaje profundo y complejo, no exento de errar. Es ante todo un despliegue hacia el sí mismo, del que se sale interrogado y extenuado, no solo por las preguntas que emergen y los desafíos que entraña este sendero, sino más bien porque al final del camino se corre el riesgo de quedar atrapado en lo que se ha denominado en este escrito, el reino de la razón poética, en cuyo seno más que a razonar y a definir, a lo que invita es a sentir (lo que puede llegar a ser la revelación). De ahí que, frente a lo sagrado, es decir frente a lo indescriptible, lo mejor será callar. Hacer votos de silencio, finalmente traducidos, ojalá, en acciones de amor.

Referencias

Andreu, A. (2010). Fundamentación teológica de la razón poética. Aurora, 11, 6-17.

Bundgård, A. (2005). El liberalismo espiritual de María Zambrano: Horizonte del liberalismo. Revista de Estudios Culturales Españoles, 6(1), 25-41. DOI: 10.1080/1463620042000336893

Gómez, G. (1992). El camino de la razón poética. Málaga: Ágora. 
Larrosa, J., \& Aparici, B. (2000). Aprender de oído. El aula, el claro y la voz en María Zambrano. Revista Educación y Pedagogía, 12(26-27), 39-46.

Maillard, C. (1992). La creación por la metáfora. Introducción a la razón poética. Barcelona: Anthropos.

Moreno Sanz, J. (1995). Roce adivinatorio, mirada remota. Lógica musical del sentir en María Zambrano. Isegoría. Revista de Filosofía Moral y Política,11, 162-176. DoI: 10.3989/isegoria.1995.i11.260

Moreno Sanz, J. (1996). Estudio introductorio. En: Zambrano, M. Horizonte del liberalismo (9-194). J. Moreno Sanz (Ed.). Madrid: Morata.

Ortega Muñoz, J. F. (1996). Reflexión y revelación. Los dos elementos del discurrir filosófico. (Una aproximación la pensamiento de María Zambrano). Contrastes. Revista Interdisciplinar de Filosofia, 1, 211-239. DoI: 10.24310/ Contrastescontrastes.v1i0.1875

Ortega y Gasset, J. (1993). Obras completas (Tomo I). Madrid: Alianza Editorial, Revista de Occidente.

Revilla, C. (2003). Acerca del lenguaje de la razón poética. Signos filosóficos, 9, 81-98.

Rivara Kamaji, G. (2002). La función de la metáfora en la razón poética de María Zambrano. Acta poética, 23(1-2), 93-108.

Tello, E. (2015). Una poética posible para María Zambrano: sobre el adormirse en el bosque como lectura reparadora. Aurora, 16, 114-124.

Trueba, V. (2009). De la metafísica a la lógica (sobre María Zambrano y Chantall Maillard). Boletin de la Biblioteca de Menéndez Pelayo, LXXXV, 385-406.

Zambrano, M. (1986). De la aurora. Madrid: Turner.

Zambrano, M. (1987). El pensamiento vivo de Séneca. Madrid: Cátedra.

Zambrano, M. (1989a). Delirio y destino. Madrid: Grafur.

Zambrano, M. (1989b). Notas de un método. Madrid: Mondadori.

Zambrano, M. (1989c). La reforma del entendimiento. En: Senderos (pp.73-80). Barcelona: Anthropos.

Zambrano, M. (1989d). Los intelectuales en el drama de España. En: Senderos (pp. 27-70). Barcelona: Anthropos.

Zambrano, M. (1989e). Misericordia. En: Senderos (pp. 120-146). Barcelona: Anthropos. 
Zambrano, M. (1989f). San Juan de la Cruz. De la 'noche oscura' a la más clara mística”. En: Senderos (pp. 184-198). Barcelona: Anthropos.

Zambrano, M. (1989g). La guerra, de Antonio Machado. En: Senderos (pp. 6070). Barcelona: Anthropos).

Zambrano, M. (1992). Persona y democracia. Barcelona: Anthropos.

Zambrano, M. (1996). Horizonte del liberalismo. J. Moreno Sanz (Ed.). Madrid: Morata.

Zambrano, M. (2000a). Hacia un saber sobre el alma. Madrid: Alianza.

Zambrano, M. (2000b). La agonía de Europa. Madrid: Trotta.

Zambrano, M. (2004). La razón en la sombra. Antología crítica. J. Moreno Sanz (Ed.). Madrid: Siruela.

Zambrano, M. (2010). Filosofía y poesía. México: Fondo de Cultura Económica. Zambrano, M. (2011a). Escritos sobre Ortega. R. Tejada (Ed.). Madrid: Trotta.

Zambrano, M. (2011b). Claros del bosque. M. Gómez Blesa (Ed.). Madrid: Cátedra. 